\title{
Calcium Absorption from the Ingestion of Coral-Derived Calcium by Humans
}

\author{
Kunihiko Ishitani, ${ }^{1}$ Eiko Itakura, ${ }^{1}$ Shiro Goto ${ }^{2}$ \\ and Takatoshi EsASHI ${ }^{3}$ \\ ${ }^{1}$ Higashi Sapporo Hospital, Sapporo 003-8585, Japan \\ ${ }^{2}$ Formerly, Tokyo University of Agriculture, Ichikawa 272-0035, Japan \\ ${ }^{3}$ Division of Applied Food Research, The National Institute \\ of Health and Nutrition, Tokyo 162-8636, Japan
}

(Received September 20, 1998)

\begin{abstract}
Summary Recent dietary life involves frequent opportunities for the ingestion of purified, processed food products and preserved foods, and it has been pointed out that the current dietary mineral intake strongly tends toward nutritional imbalance. The Ryukyu Islands yield coral which contains calcium and magnesium in a content ratio of about 2 to 1 , with their approximate contents of 20 and $10 \%$, respectively. In this report, the calcium absorption from the ingestion of crackers into which the coral powder was incorporated (coral-added crackers) and that from ingestion of calcium carbonate-added crackers was comparatively assessed. Twelve healthy adult volunteers ( 6 men and 6 women) ingested coral-added crackers (calcium content: $525 \mathrm{mg}$ ) and calcium carbonate-added crackers (ditto) once each alternately on a cross-over design with a wash-out period of $3 \mathrm{~d}$ between the regimens. The study also included controls receiving neither cracker. The degree of intestinal absorption of calcium from coral-added crackers and that from calcium carbonate-added crackers was evaluated in terms of increment in urinary calcium excretion per $\mathrm{dL}$ of glomerular filtrate (GF) (difference between coral calcium and calcium carbonate) and increase in urinary calcium excretion per mlligram creatinine (difference from control value). The increment in urinary calcium excretion per $\mathrm{dL}$ of GF during the latter half of the observation period after the ingestion of coral-added crackers was significantly greater than that during the latter half of the observation period after ingestion of calcium carbonate-added crackers ( $p=0.039$, paired $t$-test). A significant difference (from control value) in the increase of urinary calcium excretion per milligram creatinine was also observed $(p=0.0008)$. The present data, though from a relatively few study subjects, suggest that the calcium of coral origin is better absorbed from the intestine than calcium of calcium carbonate origin on the average.
\end{abstract}

Key Words coral calcium, calcium absorption, urinary calcium excretion 
According to the Proposed Diagnostic Criteria for Osteoporosis (Japanese Society for Bone Metabolism) (1), as many. as roughly ten million Japanese persons are estimated to be diagnosed as having osteoporosis, which thus is the most common disease in Japan.

A therapeutic or prophylactic approach to osteoporosis, or to suppression of decrease in bone mass, is calcium supplementation. The underlying mechanism is generally thought to consist in the suppression of parathyroid hormone secretion (2). Recently, stress is laid particularly on the importance of a well-balanced supply of calcium and magnesium rather than simple calcium intake (3).

In their epidemiological study on the relationship of cardiac disorders to calcium/magnesium intake ratio in 1940, Karppanen et al (4) pointed out that the number of patients with cardiac disorder was prone to increase with rising calcium/magnesium ratio. Additionally, cardiac disorders were found to be of the highest in incidence in Finland where the intake ratio exceeded $4: 1$.

It has also been demonstrated by Seelig et al (5) in a balance test with a daily magnesium intake of $350 \mathrm{mg}$ and a progressively increasing daily calcium intake of 200 to $1,400 \mathrm{mg}$ that urinary magnesium excretion increased with increasing calcium intake, leading eventually to a negative balance with excessive magnesium excretion over its actual intake. The nutritional requirement for calcium is $600 \mathrm{mg}$ a day and the recommended daily magnesium intake is $300 \mathrm{mg}$ in Japan. It may thus be said that a calcium:magnesium intake ratio of $2: 1$ is advisable for Japanese (6).

Ryukyuan coral is a dietary material approved as a food additive that contains calcium and magnesium in an approximate ratio of $2: 1$, with their contents of 20 and $10 \%$, respectively. Under the view that it is justified to add this foodstuff to the so-called nutritionally well-balanced foods which satisfy the mineral balance, we incorporated coral powder into inexpensive, light, tasty crackers. This foodstuff was incorporated into crackers to permit a well-balanced mineral intake of about half the daily requirements of calcium and magnesium (i.e., $300 \mathrm{mg}$ calcium and $150 \mathrm{mg}$ magnesium) by the daily ingestion of 4 crackers (per box) as a snack.

This study was undertaken to evaluate in humans whether mean intestinal absorption of coral-derived calcium incorporated into crackers (hereinafter referred to as coral-added crackers) might be comparable or even superior to mean intestinal absorption of calcium carbonate-derived calcium in crackers.

\section{METHODS}

Subjects. Twelve normal subjects (6 men and 6 women; their ages, body weights and heights shown in Table 1) participated in the study after giving written informed consent. The study was designed in accordance with the spirit of the Declaration of Helsinki (adopted in 1964; as amended in 1989) (7) and conducted after review and approval by the Higashi Sapporo Hospital Institutional Review Board. None of the subjects had a history of bone disease, peptic ulcer, enterectomy, regional enteritis, malabsorption, nephrolithiasis, liver cirrhosis, or renal disorder. The 
Table 1. Background characteristics of subjects.

\begin{tabular}{clccc}
\hline Subject & Gender & Age $(\mathrm{y})$ & Height $(\mathrm{cm})$ & Body weight $(\mathrm{kg})$ \\
\hline M1 & Male & 41 & 165 & 61 \\
M2 & Male & 33 & 172 & 55 \\
M3 & Male & 24 & 173 & 73 \\
M4 & Male & 29 & 178 & 60 \\
M5 & Male & 39 & 171 & 59 \\
M6 & Male & 23 & 165 & 63 \\
F1 & Female & 23 & 165 & 54 \\
F2 & Female & 20 & 156 & 46 \\
F3 & Female & 38 & 153 & 63 \\
F4 & Female & 28 & 153 & 40 \\
F5 & Female & 32 & 155 & 44 \\
F6 & Female & 33 & 168 & 56 \\
\hline
\end{tabular}

Male: age $31.5 \pm 6.9$, height $170.7 \pm 4.6$, weight $61.8 \pm 5.6$.

Female: age $29.0 \pm 6.1$, height $158.3 \pm 5.9$, weight $50.5 \pm 7.9$.

Overall: age $30.3 \pm 6.6$, height $164.5 \pm 8.1$, weight $56.2 \pm 8.9$.

subjects had not taken calcium supplements or vitamin D preparations, nor received anticonvulsants, diuretics, adrenocorticosteroids, estrogens or any other drugs that could affect calcium metabolism during the month preceding the start of the study.

Methods. The subjects were divided into two groups; subjects of one group ingested coral-added crackers first (group A) and those of the other group ingested calcium carbonate-added crackers first (group B). After a subsequent 3-d wash-out period, the groups received the study regimens on a cross-over design. An additional group (group C) served as a control not ingesting crackers. In order to sharpen calcium absorption, all study subjects were so instructed as to adhere to a daily diet restricted in calcium $(300 \mathrm{mg} / \mathrm{d}$, corresponding to half the dietary allowance), magnesium $(150 \mathrm{mg} / \mathrm{d}$, corresponding to half the aimed intake) and sodium (2.3 $\mathrm{g} / \mathrm{d}$, corresponding to half the dietary allowance) beginning $2 \mathrm{~d}$ prior to the start of study regimens.

Each 12 -g piece of coral-added cracker contained $75 \mathrm{mg}$ of calcium and $36 \mathrm{mg}$ of magnesium. Calcium and magnesium contents of a $12-\mathrm{g}$ calcium carbonate-added cracker were 75 and $6 \mathrm{mg}$, respectively. Each subject ingested seven pieces of either cracker each time in this study since, according to Harvey et al (8), oral ingestion of $500 \mathrm{mg}$ of calcium suffices for adequate evaluation of intestinal calcium absorption by measurements of urinary calcium excretion. The calcium intake and magnesium intake after the ingestion of 7 coral-added crackers were calculated to be 525 and $252 \mathrm{mg}$, respectively, and those after ingestion of 7 calcium carbonate-added crackers to be 525 and $42 \mathrm{mg}$, respectively.

Controls (group C) did not ingest either cracker at all.

During each phase of the study, all subjects fasted from 8:00 p.m. of the 
preceding day, but were allowed to drink $300 \mathrm{~mL}$ of distilled water at 8:00 and 11:00 p.m. of that day and $600 \mathrm{~mL}$ of distilled water at 6:00 a.m. of the test day.

A 2-h urine collection was obtained from each subject from 6:00 to 8:00 a.m. ( $2 \mathrm{~h}$ pre-ingestion). At 8:00 a.m., subjects of group A ingested an initial regimen consisting of coral-added crackers and those of group B ingested an initial regimen consisting of calcium carbonate crackers, with $300 \mathrm{~mL}$ of distilled water. Another 2-h urine collection was then obtained from 8:00 to 10:00a.m. (first half of observation period). At 10:00 a.m., each subject drank $300 \mathrm{~mL}$ of distilled water and urine was collected for $2 \mathrm{~h}$ from 10:00 a.m. to noon (latter half of observation period). An additional 2-h collection from noon to 2:00 p.m. was also obtained for reference. Controls of group $\mathrm{C}$ ingested distilled water alone at these timepoints, each followed by 2-h urine collection (i.e., 08:00-10:00 and 10:00-12:00).

Procedure for evaluation of calcium absorption. In this study, the calcium absorption from the intestinal tract was evaluated on the basis of urinary calcium excretion as reported by Harvey et al (8), Nicar and Pak (9), Pak et al (10), Broadus et al (11), Birge et al (12), and Dokkum et al (13). Particularly, for comparative assessments of the absorption of calcium from coral-added crackers versus that from calcium carbonate-added crackers, measurements were carried out with the following five assay methods of Nicar and Pak and Harvey et al. Method 1) Urinary calcium excretion (in $\mathrm{mg}$ ) per milligram of creatinine during the first $4 \mathrm{~h}$ post-ingestion from 8:00 a.m. to noon. Method 2) Increment in urinary calcium excretion (in $\mathrm{mg}$ ) per $\mathrm{dL}$ of $\mathrm{GF}$ during the latter half of the observation period, calculated by subtracting pre-ingestion urinary calcium excretion (6:00-8:00 a.m.) from post-ingestion urinary calcium excretion (10:00 a.m.-noon). Method 3) Increment in urinary calcium excretion (in $\mathrm{mg}$ ) per $\mathrm{dL}$ of GF during the first half of the observation period, calculated by subtracting from post-ingestion urinary calcium excretion (8:00-10:00 a.m.). Method 4) Urinary calcium excretion (in mg) calculated by subtraction of the urinary calcium excretion per milligram creatinine in non-cracker-ingested controls over $4 \mathrm{~h}$, from 8:00 a.m. to noon, from post-ingestion urinary calcium excretion per milligram creatinine during $4 \mathrm{~h}$, from 8:00 a,m. to noon. Urinary calcium excretion in $\mathrm{mg} / \mathrm{dL}$ of $\mathrm{GF}$ was calculated by multiplying urinary calcium excretion (in $\mathrm{mg}$ ) per milligram urinary creatinine by serum creatinine concentration (in $\mathrm{mg} / \mathrm{dL}$ ). (Blood collection was performed at 8:00 a.m. just prior to cracker ingestion and at noon (i.e., $2 \mathrm{~h}$ post-ingestion), and serum creatinine levels determined at these timepoints were used for the calculation.) Method 5) Determine the increase in serum calcium concentration (in $\mathrm{mg} / \mathrm{dL}$ ) by subtracting the serum calcium concentration in non-cracker-ingested controls from post-ingestion serum calcium concentration. Similar procedures were used for the evaluation of magnesium absorption. Inter-group comparisons were made using a paired $t$-test.

Urine samples were analyzed for calcium by the OCPC method ("Jisseiken" $\mathrm{Ca}$, an autoanalyzer system reagent; DIA-Iatron Co., Ltd., Tokyo, Japan), and for magnesium by the xylidyl blue method ("Jisseiken" $\mathrm{Mg}$, an autoanalyzer system 
Table 2. Calcium absorption from the intestine and serum calcium concentration following ingestion of calcium-supplemented crackers.

\begin{tabular}{|c|c|c|}
\hline & $\mathrm{CaCO}_{3}$-added cracker & Coral-added cracker \\
\hline \multicolumn{3}{|l|}{ Pre-ingestion } \\
\hline $\begin{array}{l}\text { Urinary Ca (8:00-10:00 a.m.) } \\
\mathrm{mg} / \mathrm{dL} \text { GF }\end{array}$ & $0.035 \pm 0.019$ & $0.029 \pm 0.012$ \\
\hline \multicolumn{3}{|l|}{ Method 1) } \\
\hline $\begin{array}{l}\text { Urinary Ca (8:00-noon) } \\
\mathrm{mg} / \mathrm{mg} \mathrm{Cr}\end{array}$ & $0.236 \pm 0.064$ & $0.325 \pm 0.020^{+}$ \\
\hline \multicolumn{3}{|l|}{ Method 2) } \\
\hline $\begin{array}{l}\text { Increase in urinary } \mathrm{Ca} \\
\text { (10:00-noon; latter half phase) } \\
\text { mg/dLGF }\end{array}$ & $0.053 \pm 0.040$ & $0.075 \pm 0.036^{++}$ \\
\hline \multicolumn{3}{|l|}{ Method 3) } \\
\hline $\begin{array}{l}\text { Increase in urinary } \mathrm{Ca} \\
(8: 00-10: 00 ; \text { first half phase }) \\
\mathrm{mg} / \mathrm{dL} \text { GF }\end{array}$ & $0.015 \pm 0.0020$ & $0.034 \pm 0.032$ \\
\hline \multicolumn{3}{|l|}{ Method 4) } \\
\hline $\begin{array}{l}\text { Increase in urinary } \mathrm{Ca} \\
(8: 00-\text { noon } ; \Delta \text { from control }) \\
\mathrm{mg} / \mathrm{mg} \mathrm{Cr}\end{array}$ & $0.055 \pm 0.083$ & $0.144 \pm 0.061^{* *}$ \\
\hline \multicolumn{3}{|l|}{ Method 5) } \\
\hline $\begin{array}{l}\text { Increase in serum } \mathrm{Ca} \\
\text { (8:00-noon; } \Delta \text { from control) } \\
\mathrm{mg} / \mathrm{dL}\end{array}$ & $0.142 \pm 0.127^{*}$ & $0.228 \pm 0.149^{* *}$ \\
\hline
\end{tabular}

Mean \pm SD. Significant difference from control: $* p<0.05$, $* * p<0.01$. Significant difference between regimens: ${ }^{+} p<0.05,{ }^{++} p<0.01$.

reagent; DIA-Iatron). The urinary creatinine concentration was determined by the enzymatic method (CRE-L; Serotec Inc., Sapporo, Japan). Calcium, magnesium and creatinine concentrations in serum samples were determined by the same methods as for the urine assays.

\section{RESULTS}

\section{Calcium absorption}

Pertinent data are presented in Table 2. The group receiving coral-added crackers and that receiving calcium carbonate-added crackers were practically comparable with respect to urinary calcium excretion during 2-h pre-ingestion (6:00-8:00 a.m.). Mean urinary calcium excretion after the ingestion of coral-added crackers was greater than that after calcium carbonate-added crackers by four determination methods, 1) through 4). Significant intergroup differences were noted in urinary calcium excretion $(\mathrm{mg} / \mathrm{mg} \mathrm{Cr})$ during 2-h pre-ingestion (6:00-8:00 a.m.) 
Table 3. Increase in urinary calcium excretion $(\mathrm{mg})$ per $\mathrm{dL}$ of glomerular filtrate during the latter half of the observation period (10:00 a.m.-noon) after cracker ingestion in individual subjects.

\begin{tabular}{ccc}
\hline Subject & $\mathrm{CaCO}_{3}$-added cracker & Coral-added cracker \\
\hline M1 & 0.094 & 0.094 \\
M2 & 0.075 & 0.067 \\
M3 & 0.039 & 0.085 \\
M4 & 0.082 & 0.116 \\
M5 & 0.132 & 0.106 \\
M6 & 0.087 & 0.125 \\
F1 & 0.029 & 0.047 \\
F2 & 0.053 & 0.062 \\
F3 & 0.009 & 0.015 \\
F4 & 0.024 & 0.110 \\
F5 & 0.012 & 0.021 \\
F6 & 0.004 & 0.053 \\
\hline Overall & $0.053 \pm 0.040$ & $0.075 \pm 0.036$ \\
Paired $t$-test & & \\
$p=0.039$ & $0.085 \pm 0.030$ & $0.099 \pm 0.021$ \\
Males & & \\
$p=0.031$ & $0.022 \pm 0.017$ & $0.051 \pm 0.033$ \\
Females & & \\
$p=0.059$ & &
\end{tabular}

Mean \pm SD.

by Method 1), increase in urinary calcium excretion (mg/dL GF) during the latter half of the post-ingestion observation period (10:00 a.m. to noon) by Method 2), and increase in urinary calcium excretion ( $\Delta$ from control, $\mathrm{mg} / \mathrm{mg} \mathrm{Cr}$ ) during 4 -h post-ingestion (8:00 a.m. to noon) by Method 4). However, no significant difference was demonstrated for the first half of the post-ingestion observation period (8:00-10:00 a.m.) by Method 3). These findings were generally in line with the conclusions from absorption studies on calcium citrate versus calcium carbonate by Harvey et al ( 8 ) and Nicar and Pak (9) that calcium citrate was better absorbed.

The increase in serum calcium concentration calculated by subtraction of the control value from the post-ingestion serum calcium value (Method 5)) also showed a significant difference between the two groups; hence, a similar tendency to that reported by Harvey et al.

Individual assay data for the latter half of the post-ingestion observation period are presented in Table 3.

The males exhibited a better calcium absorption from coral-derived calcium as compared with the females, though the subject sample sizes were small.

Meanwhile, the increase in urinary calcium excretion during the subsequent 2-h period (noon to 2:00 p.m.), determined for reference, showed a plateau with no 
Table 4. Increase in urinary magnesium excretion $(\mathrm{mg})$ per $\mathrm{dL}$ of glomerular filtrate and serum magnesium concentration during the latter half of the observation period (10:00 a.m.-noon) after cracker ingestion.

\begin{tabular}{lcc} 
& $\mathrm{CaCO}_{3}$-added cracker & Coral-added cracker \\
\hline $\begin{array}{l}\text { Increase in urinary } \\
\text { magnesium excretion }\end{array}$ & $0.016 \pm 0.014$ & $0.038 \pm 0.022^{++}$ \\
$\quad \begin{array}{l}\text { Paired } t \text {-test } \\
p=0.001\end{array}$ & \\
Increase in serum magnesium \\
concentration (8:00-10:00 a.m.) \\
$\quad$ mg/dL \\
$\quad \begin{array}{l}\text { Paired } t \text {-test } \\
p=0.006\end{array}$
\end{tabular}

Mean \pm SD. Significant difference between regimens: ${ }^{+} p<0.05,{ }^{++} p<0.01$.

appreciable difference between the two cracker regimens. It was thus considered appropriate to assess the responses by analyzing two consecutive 2-h post-ingestion urine samples for the comparison based on urinary calcium excretion.

\section{Magnesium absorption}

Intestinal magnesium absorption and increases in serum magnesium concentration following ingestion of the test crackers are shown in Table 4.

The magnesium content of the coral-added cracker was as high as $252 \mathrm{mg}$ while that of the calcium carbonate-added cracker was only $42 \mathrm{mg}$. Significant intergroup differences were observed in respect of increment in urinary magnesium excretion during the latter half of the post-ingestion observation period (10:00 a.m. to noon) by Method 2) $(p=0.001)$, and there was an increase in serum magnesium concentration at noon as compared to the serum magnesium value at 8:00 a.m. $(p=0.006)$.

\section{DISCUSSION}

The assessments of calcium absorption from supplemented crackers performed using five methods as described by Harvey et al (8) and Nicar and Pak (9) demonstrated a better absorption of coral-derived calcium than that of calcium carbonate-derived calcium on the average.

A laboratory study in rats to explore the ability to utilize calcium derived from Ryukyuan coral which contains calcium and magnesium at a ratio of about 2-to-1 has been reported by Suzuki et al (14). The investigators calculated the calcium balance from excretions in the feces and urine during the last $3 \mathrm{~d}$ of a 4 -wk rat feeding trial using coral. They concluded that the efficiency of calcium utilization was satisfactorily greater with coral-derived calcium as compared to calcium 
carbonate-derived calcium, although the difference observed did not attain a level of statistical significance.

Suzuki et al also described that their concurrent test with a fivefold increase in dietary magnesium intake (i.e., $0.25 \%$ as against $0.05 \%$ ) demonstrated a marked increase in urinary calcium excretion; hence, a better calcium absorption in the group fed on high-magnesium $(0.25 \%)$ diet.

The present study was conducted under conditions with a higher rate of magnesium content (6-fold difference) as compared to the above two laboratory studies of Suzuki et al, viz. a magnesium content of $36 \mathrm{mg}(0.3 \%)$ per 12 -g coral-added cracker versus a magnesium content of $6 \mathrm{mg}(0.05 \%)$ per 12 -g calcium carbonate-added cracker.

While Suzuki et al have given no account of the high efficiency of calcium utilization from coral in their article, it would be reasonable to assume that the high magnesium content has some bearing upon the intestinal absorption of calcium when viewed together with consideration of the present human trial data. However, it is of importance to mention that problems such as coral calcium solubility in gastric acid, absorption from the intestine and reabsorption from the renal tubules per se should be discussed. Additionally, the potential involvement of magnesium and further basic studies are needed.

The present data demonstrating the remarkably good absorption of calcium from coral containing calcium and magnesium in a ratio of 2-to-1 are of profound interest, and it is anticipated that Ryukyuan coral can be incorporated into a variety of inexpensive, light, tasty foods so as to enable a ready dietary intake of calcium and magnesium in a ratio of 2 -to- 1 .

The authors are gratefully indebted to Dr. Osamu Setoyama, Vice Director of the Clinical Division, Higashi Sapporo Hospital, and dietitians and other staff of the hospital for helpful discussion and expert cooperation throughout this study.

\section{REFERENCES}

1) Proposed Diagnostic Criteria for Osteoporosis (Jpn. Soc. Bone Metab., 1993).

2) Recker RR. 1981. Continuous treatment of osteoporosis: Current status. Orthop Clin North Am 12: 611-627.

3) Esashi T. 1992. Calcium and magnesium. Rinsho Eiyo (Clin Nutr) 81: 288-294.

4) Karppanen H, Pennanen R, Passinen L. 1978. Minerals, coronary heart disease and sudden coronary death. Adv Cardiol 25: 9-24.

5) Seelig MS. 1982. Magnesium requirements in human nutrition. J Med Soc 79: 849-850.

6) Itokawa Y. 1990. Magnesium as a nutrient. Igaku no Ayumi (J Clin Exp Med) 154: 213-216.

7) The Declaration of Helsinki (adopted in 1964; as amended in 1989). 1988. J Nutr Sci Vitaminol 51: 41-42.

8) Harvey JA, Zobitz MM, Pak CYC. 1988. Dose dependency of calcium absorption: A comparison of calcium carbonate and calcium citrate. J Bone Mineral Res 3: 253-258.

9) Nicar MJ, Pak CYC. 1985. Calcium bioavailability from calcium carbonate and calcium 
citrate. J Clin Endocrinol Metab 61: 391-395.

10) Pak CYC, Harvey JA, Hsu MC. 1987. Enhanced calcium bioavailability from a solubilized form of calcium citrate. J Clin Endocrinol Metab 65: 801-805.

11) Broadus AE, Dominguez M, Bartter FC. 1978. Pathophysiological studies in idiopathic hypercalciuria: Use of an oral calcium tolerance test to characterize distinctive hypercalciuric subgroups. $J$ Clin Endocrinol Metab 47: 751-760.

12) Birge SJ, Peck WA, Berman M, Whedon GD. 1969. Study of calcium absorption in man: A kinetic analysis and physiologic model. J Clin Invest 48: 1705-1713.

13) van Dokkum W, de la Gueronniere V, Schaafsma G, Bouley C, Luten J, Latge C. 1996. Bioavailability of calcium of fresh cheeses, enteral food and mineral water: A study with stable calcium isotopes in young adult women. Br J Nutr 75: 893-903.

14) Suzuki K, Uehara M, Masuyama R, Gotou S. 1997. Calcium utilization from natural coral calcium-A coral preparation with a calcium-magnesium content ratio of $2: 1$. Abstracts of Papers Presented at the 44th Jpn. Soc. Nutr. Betterment, p. 145, Fukuoka. 